\title{
KONSEP PENATAAN RUANG TERBUKA HIJAU DI KORIDOR JALAN RAYA PORONG SEBAGAI UPAYA PENINGKATAN ESTETIKA KOTA
}

\author{
Mochamad Idris Efendy**) A.A.G. Agung Ramayadnya*)
}

\begin{abstract}
Abstrak
Kondisi eksisting ruang terbuka hijau di koridor Jalan Raya Porong masih kurang.Berkurangnya ruang terbuka hijau menyebabkan meningkatnya permasalahan lingkungan salah satunya lingkungan menjadi gersang dan panas.Konsep penataan ruang terbuka hijau di koridor Jalan Raya Porong diharapkan bermanfaat sebagai pengendali pencemaran dan berfungsi sebagai sarana peningkatan nilai estetika kawasan. Penelitian ini bertujuan untuk menentukan konsep penataan koridor jalan Jalan Raya Porong dalam rangka meningkatkan estetika kota. Analisis yang digunakan adalah analisis teori unsur urban design (8 elemen unsur pembentuk ruang kota) dengan metode deskriptif kualitatif. Analisis Figure Ground, Linkage, dan Place dengan metode deskriptif kualitatif.Hasil penelitian ini menunjukkan bahwa dengan menggunakan metode analisis teori unsur urban design (8 elemen unsur pembentuk ruang kota) menghasilkan gambaran tentang kondisi ruang terbuka hijau di koridor Jalan Raya Porong. Hasil metode analisis Figure Ground, Linkage, dan Place pada penelitian ini menghasilkan konsep penataan ruang terbuka hijau di koridor Jalan Raya Porong yang bisa menunjang kualitas lingkungan dan meningkatkan estetika kota.
\end{abstract}

Kata Kunci : Estetika, Figure Ground, Koridor, Linkage, Place, dan Ruang Terbuka Hijau

\section{PENDAHULUAN}

Sidoarjo merupakan salah satu kabupaten di Jawa Timur yang mengalami perkembangan pesat terutama di bidang industri, perdagangan, dan jasa. Hal ini disebabkan oleh letak KabupatenSidoarjo berbatasan dengan Kota Surabaya yang menyebabkan KabupatenSidoarjo mendapat dampak langsung pengembangan ekonomi akibat hubungan kegiatan perekonomian antara Kota Malang, Pasuruan dan Surabaya. Kegiatan sirkulasi kendaraan yang padat dan pembangunan terus terjadi seiring perekonomian yang meningkat sehingga dapat menyebabkan munculnya permasalahan spasial wilayah. Permasalahan transportasi menjadi sebuah objek yang tidak asing lagi di kawasan jalur perkotaan.Permasalahan berupa kemacetan lalu lintas berpengaruh langsung terhadap kenyamanan bagi setiap penduduk Kabupaten Sidoarjo.

Luas total wilayah Kabupaten Sidoarjo sebesar 71.424,25 Ha. Akhir tahun 2012, berdasarkan data dari registrasi penduduk, jumlah penduduk di Kabupaten Sidoarjo sebanyak 2.053.467 jiwa. Jumlah penduduk yang padat akan mengakibatkan kegiatan pembangunan semakin meningkat serta dapat berdampak pada semakin berkurangnya ruang terbuka hijau. Permasalahan utama yang sering dijumpai dalam keberadaan ruang terbuka hijau adalah semakin berkurangnya ruang terbuka hijau karena keterbatasan lahan dan ketidakkonsistenan dalam penerapan tata ruang. Berkurangnya ruang terbuka hijau disebabkan oleh konversi lahan yaitu beralih fungsinya ruang terbuka hijau untuk peruntukan ruang yang lain. Kebutuhan ruang di Kabupaten Sidoarjo turut meningkat seiring dengan kegiatan pembangunan di bidang ekonomi dan meningkatnya pertambahan penduduk. Pemenuhan kebutuhan ruang bagi kegiatan ekonomi dan penduduk Kabupaten Sidoarjo kemungkinan besar dapat mengubah ruang terbuka hijau menjadi kawasan perdagangan, industri maupun permukimanpermukiman penduduk. Dengan berkurangnya ruang terbuka hijau akan dapat mengakibatkan semakin meningkatnya permasalahan lingkungan. (http://Ruang Terbuka Hijau RTH_EDUKASI.htm)

Pertambahan jumlah penduduk yang signifikan tentu juga akan mempengaruhi dari keberadaan open space. Semakin bertambahnya jumlah penduduk maka kebutuhan ruang terbangun semakin bertambah.Jumlah penduduk di Kabupaten Sidoarjo mengalami kenaikan yang cukup tinggi. Pada data lima tahun terakhir yaitu dimulai pada tahun 2008 jumlah penduduk

\footnotetext{
**) Mahasiswa PWK

*) Dosen PWK

Universitas PGRI Adi Buana Surabaya
} 
Kabupaten Sidoarjo sebanyak 1.964 .759

jiwa, pada tahun 2009 mengalami peningkatan sehingga menjadi 2.018.239 jiwa, pada tahun 2010 sebanyak 2.018.239 jiwa, pada tahun 2011 mengalami peningkatan penurunan menjadi 1.984 .486 jiwa, dan pada tahun 2012 mengalami peningkatan yang cukup tinggi yaitu mencapai 2.053.467 jiwa. Permasalahan akan semakin sulit terpenuhi pemenuhan standart akan kebutuhan ruang terbuka hijau di wilayah perkotaan. (BPS Kabupaten Sidoarjo, 2012)

Ruang terbuka hijau memiliki beberapa fungsi, antara lain sebagai pengaman keberadaan kawasan lindung perkotaan, sebagai pengendali pencemaran dan kerusakan tanah, air,dan udara, serta sebagai sarana estetika kota. Keberadaan ruang terbuka hijau yang penting ini kurang mendapat perhatian, terutama dalam tata letak penempatannya. Dengan diketahuinya lokasi-lokasi yang tepat dalam penempatan ruang terbuka hijau, fungsi ruang terbuka hijau dapat dimaksimalkan dalam hal peningkatan nilai estetika kawasan kota serta dapat memberikan nilai lebih dalam hal kenyamanan. Penentuan jarak antar ruang terbuka hijau menjadi hal penting sehingga fungsi ruang terbuka hijau dapat efektif dalam menciptakan suasana yang nyaman.

Data masterplan ruang terbuka hijau Kabupaten Sidoarjo tahun 2010 menerangkan bahwa kebutuhan akan ruang tebuka hijau di Kabupaten Sidoarjo masih jauh dari pemenuhan. Pada Undang-undang No. 26 Tahun 2007 tentang Penataan Ruang menjelaskan perencanaan tata ruang wilayah kota harus memuat rencana penyediaan dan pemanfaatan ruang terbuka hijau yang luas minimalnya sebesar $30 \%$ dari luas wilayah kota. Ruang terbuka hijau di perkotaan terdiri dari ruang terbuka hijau publik dan ruang terbuka hijau privat dimana proporsi ruang terbuka hijau pada wilayah perkotaan adalah sebesar minimal $30 \%$ yang terdiri dari $20 \%$ ruang terbuka.

\section{METODE PENELITIAN}

Penelitian tentang ruang terbuka hijau di koridor Jalan Raya Porong ini merupakan penelitian deskriptif kualitatif.Penelitian ini menggunakan dua jenis data dalam pembahasannya, yaitu data primer dan data sekunder. Data primer dapat dilakukan salah satunya dengan cara observasi, sedangkan data sekunder berupa data survei, kumpulan data, peta, tabel dan uraian terkait. Tujuan untuk mencapai suatu konsep penataan ruang terbuka hijau yang ideal di kawasan koridor Jalan Raya Porong digunakan beberapa teknik analisa, dalam langkah mengidentifikasi karakteristikkondisi ruang terbuka hijau di koridor Jalan Raya Porong digunakan teknik analisa deskriptif kualitatif dengan menggunakan teori unsur urban design (8 elemen unsur pembentuk ruang kota, Hamid Shirvany). Selanjutnya untuk menentukan konsep penataan ruang ruang terbuka hijau di koridor Jalan Raya Porong digunakan analisa Figure Ground, Linkage, dan Place.Dalam penelitian yang berjudul "Konsep Penataan Ruang Terbuka Hijau Di Koridor Jalan Raya Porong Sebagai Upaya Peningkatan Estetika Kota" ini variabel yang digunakan adalah karateristik ruang terbuka hijau dan fungsi estetika ruang terbuka hijau.Alat-alat yang dibutuhkan dalam penelitian ini meliputi Global Positioning System (GPS), Meteran, Komputer dengan perangkat lunak AutoCAD 2006, CorelDraw X4,Google SketchUp 8, serta Microsoft Word 2003. Produk akhir dari kegiatan penelitian ini adalah berupa gambar arsitekturalhasil perancangan yang terdiri dari Gambar teknis (Konsep tapak, konsep detail beberapa bagian tapak, konsep potongan tapak, konsep detail penanaman, gambar tampak, dan gambar potongan.

\section{HASIL PENELITIAN}

Analisis karakteristik kondisi ruang terbuka hijau di korodor Jalan Raya Porong terbagi menjadi 8 tinjauan analisis yaitu :

a. AnalisisPola penggunaan lahan

Pola penggunaan lahan di koridor Jalan

Raya Porong terbagi menjadi 2 segmen yaitu segmen $A\left(A^{1}, A^{2}\right)$ dan segmen $B$ $\left(B^{1}, B^{2}\right)$.

b. Analisis massa bangunan

Massa bangunan yang ada pada koridor Jalan Raya Porong tidak terlihat.Permasalahan ini diakibatkan karena adanya lumpur lapindo beserta dampaknya.

c. Analisis sirkulasi dan Perparkiran

Pada analisis sirkulasi dan perparkiran menjelaskan mengenai luas tipikal penampang koridor Jalan Raya Porong, arah sirkulasi dari arah utara yaitu dari Surabaya dan dari arah selatan yaitu Pasuruan/Malang, dan jumlah volume kendaran.Pada gambar 1 menjelaskan mengenai luasan eksisting penampang tipikal koridor Jalan Raya Porong. 


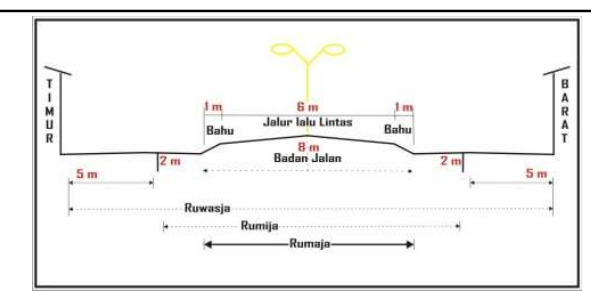

Gambar 1. Penampang Jalan Raya Porong

Pada hasil analisis aksesibilitas dan perparkiran memeliki korelasi terhadap analisis kondisi ruang terbuka hijau.Tingkat pelayanan jalan bisa menentukan pola dan fungsi kondisi ruang terbuka hijau pada koridor jalan.keseimbangan luas tipikal penampang jalan dengan penataan vegetasi dapat membentuk sebuah pola irama, pengarah, dan sebagai batas pandang pengguna yang melintas pada jalur seperti gambar $1 \& 2$.

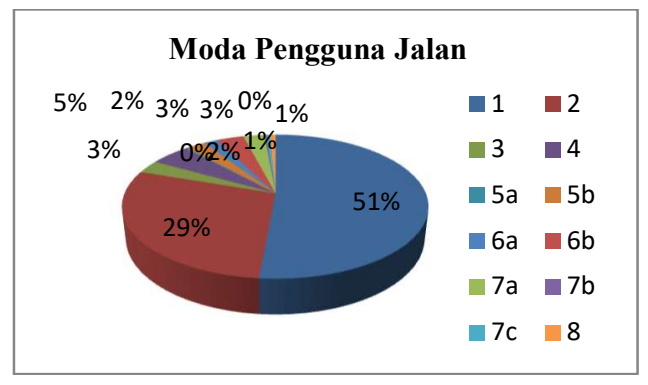

Gambar 2. Diagran Jenis Moda Pengguna Jalan

Keterangan :

1. Sepeda motor, sekuter, kendaraan roda tiga

2. Sedan, jeep, station on wagon (2 ton)

3. Oplet, combi, minibus (2 ton)

4. Pickup, microtruck, mobil hantaran (2 ton)

5.a Bus kecil (5 ton)

5.b Bus besar (8 ton) 6.a Truk ringan 2 sumbu (10 ton)

6.b Truk sedang 2 sumbu (13 ton)

7.a Truk 3 sumbu (20 ton)

7.b Truk gandeng

7.c Truk semi trailer (30 ton)

8. Kendaraan tidak bermotor

d. Ruang terbuka hijau

Persebaran dan pola ruang terbuka hijau bentuknya mengikuti pola koridor.Karateristik persebaran ruang terbuka hijau di koridor Jalan Raya Porong terbagi menjadi dua yaitu ruang terbuka hijau dan ruang terbuka non hijau. Berdasarkan data primer dari hasil observasi ruang terbuka hijau mengasumsikan prosentase ruang tebuka hijau yang ada pada koridor Jalan Raya Porong sebesar $15 \%$, ruang terbuka non hijau sebesar $80 \%$,dan sisanya $5 \%$ adalah penggunaan sebagai fasilitas umum seperti gambar 3.

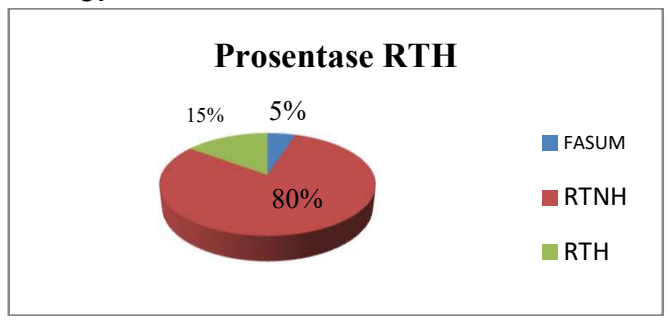

Gambar 3. Prosentase Jumlah RTH

Berdasarkan fungsinya, koridor Jalan Raya Porong dikategorikan masih jauh dari predikat jalan dengan kerapatan tanaman yang cukup, hal tersebut dilihat dari luasnya yang sekitar $1 \mathrm{Ha}$ dan suasana gersang yang ditimbulkan dari minimnya vegetasi. Posisi tanaman tersebar tidak beraturan dan tidak tertata.Tabel 3 menyajikan beberapa jenis tanaman yang terdapat pada koridor Jalan Raya Porong.

Tabel 3. Jenis Vegetasi Eksisting

\begin{tabular}{|c|c|c|c|c|c|}
\hline \multirow{2}{*}{ No } & \multirow{2}{*}{ Nama Lokal } & \multicolumn{4}{|c|}{ Jum I a h } \\
\hline & & Segmen $A^{1}$ & Segmen $A^{2}$ & Segmen $\mathrm{B}^{1}$ & Segmen $\mathrm{B}^{2}$ \\
\hline 1 & Cemara Udang & 4 & - & - & - \\
\hline 2 & Angsana & 3 & 7 & 3 & 2 \\
\hline 3 & Kelapa Gading & - & - & 2 & - \\
\hline 4 & Ketapang & 8 & 1 & 16 & - \\
\hline 5 & Palem & - & 3 & - & 4 \\
\hline 6 & Bougenville & - & 2 & - & - \\
\hline 7 & Mangga & - & 5 & 1 & 4 \\
\hline 8 & Jambu & - & 1 & 3 & - \\
\hline 9 & Bungga Sepatu & - & 1 & - & - \\
\hline
\end{tabular}

Sumber : Hasil Observasi , 2014 
e. Pedestrian

Kondisi eksisting yang ada pada koridor Jalan Raya Porong saat ini adalah tampak suasana tapak yang masih belum tertata.Sebelah kanan dan kiri tapak masih berupa tanah keras (makadam). Dengan pengertian lain bahwa keberadaan pedestrian pada koridor Jalan Raya Porong ini masih belum ada.

f. Kegiatan Pendukung

Pada saat setelah kejadian bencana lumpur, lambat waktu maka keberadaan semua kegiatan pendukung berangsurangsur hilang dari sisi kiri kanan koridor Jalan Raya Porong. Kondisi eksisting saat ini masih mengambarkan view tapak yang masih belum tertata. Kegiatan pendukung yang ada pada jalur ini biasanya hanya berupa warung-warung dan bengkel tambal ban liar di sebelah barat jalan yang mencari peluang dari beberapa sopir yang sengaja beristirahat pada tepian jalur ini.

g. Penandaan

Semua penandaan yang dimaksud adalah seperti petunjuk arah, rambu lalu lintas, tiang listrik, lampu median jalan dan beberapa media iklan yang lain. Pada kondisi eksisting di wilayah penelitian penandaan yang ada pada tapak adalah berupa lampu median jalan dengan jarak antar lampu adalah 25 meter dan tiang listrik yang ada dikedua sisi jalan dengan jarak antar tiang 25 meter .Hal ini juga tidak lepas dari minoritas aktivitas yang ada pada jalur ini.Lebih detail letak penandaan lampu median jalan dan tiang listrik yang tampak pada lokasi tapak dapat dilihat pada gambar 4 .

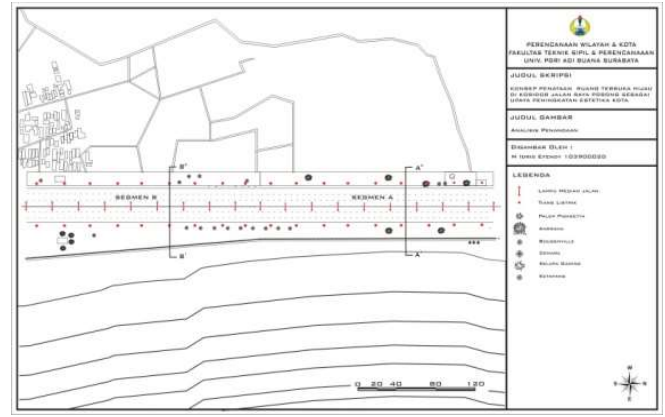

Gambar 4. Peta Analisis Penandaan

h. Preservasi

Kondisi eksisting di koridor Jalan Raya Porong sebelum ada dan meluasnya bencana lumpur wajah kawasan hanya diisi oleh beberapa fungsi bangunan yaitu bangunan industri, permukiman, dan perdagangan jasa.Bangunan di koridor Jalan Raya Porong tidak ada yang bernilai sejarah atau bangunan yang bersifat cagar budaya.

\section{Analisis Penataan Ruang Terbuak Hijau}

a. Analisis Figure Ground

Analisis Fugure ground menjadi alat terkuat untuk mengidentifikasi pola-pola tekstural melalui analisis tekstur, bentuk kota, dan pola susunan kota. Analisis Figure Ground yang ada pada koridor Jalan Raya Porong menjelaskan tentang tekstur bentuk atau pola massa bangunan yang ada pada wilayah tapak.

b. Analisis Linkage

Teori Linkage adalah teori yang membahas sistem pergerakan jalan, melihat dan mengkaji hubungan rangkaian keterkaitan titik simpul kawasan.Koridor jalan Raya Porong adalah jalur yang menhubungkan wilayah utara yaitu kawasan Surabaya dan Sidoarjo dengan wilayah selatan yaitu Pasuruan dan Malang. Maka dari itu analisis Linkage secara visual dikategorikan sebagai jalur sebagai pengait wilayah yang satu dengan wilayah yang lain.

c. Analisis Place

Place merupakan 'ruang' (space) yang memiliki suatu ciri khas, keunikan tertentu dan memiliki karakter, suatu kekuatan, keunggulan terhadap lingkungan alami, budaya setempat (Genius Loci, Nobert Schultz, 1980). Tempat atau Place dapat dibentuk dari sebuah space jika memiliki suatu ciri khas, suasana tertentu yang sangat berarti bagi pengamat, pelaku dan pengguna ruang suatu tempat. Dalam analisis Place tidak lepas dari suatu imagekota. Dalam analisis Place di koridor Jalan Raya Porong pembahasannya tidak terlepas dari teori Kevin Lynch yang berkaitan dengan citra kota atau image kota sebagai berikut :

1. Path (jalur)

Jalur koridor Jalan Raya Porong memiliki dua macam jenis sirkulasi yaitu sirkulasi jalur kendaraan dan perlintasan kerata api. Sirkulasi jalur kendaraan dengan lebar jalan $18 \mathrm{~m}$ yang terdiri dari dua ruas jalur dengan lebar setiap jalur $7 \mathrm{~m}$ dan median jalan selebar $1 \mathrm{~m}$ dengan tinggi median jalan $30 \mathrm{~cm}$ menggunakan tanah sebagai 
perkerasannya. Jalur perlintasan kereta api memeliki lebar perlintasan $3 \mathrm{~m}$.

2. Edge (tepian)

Pada pengertian dari Edge atau tepian sendiri adalah mengenai pemutus linier dan atau pembatas kawasan tertentu. Pada koridor Jala Raya Porong pembatas tepian dari jalur ini dijelaskan dengan jalur perlintasan kereta api disebelah timur jalur dengan jarak dari jalur sekitar $10 \mathrm{~m}$ dan pada sisi sebelah barat sebagai batas wilayah dibatasi oleh sungai irigasi di Desa Jatirejo Barat dengan jarak dari jalur sekitar $200 \mathrm{~m}$ dan sungai tersebut memeliki lebar $2 \mathrm{~m}$.

3. District (kawasan)

Pada koridor Jalan Raya Porong wilayah studi dijumpai sebuah district yang bisa mengambarkan ciri khas, bentuk, pola, dan wujud kawasan dimana didalamnya ada sebuah aktivitas. District atau kawasan dari koridor Jalan Raya Porong itu sendiri adalah Desa Jatirejo timur dan Desa Jatirejo barat yang menjadikan jalur ini sebagai pembatas kedua wilayah.

4. Node (simpul)

a. Pasar Porong yang ada pada sebelah selatan wilayah studi dapat dijadikan sebuah simpul kawasan dimana dengan adanya pasar tersebut terjadi sebuah pergerakan yang melibatkan koridor Jalan Raya Porong sebagi media sirkulasi menuju pasar.

b. Masjid Nurul Azhar yang berada disebelah utara sekaligus menjadi batas fisik wilayah studi merupakan sebuah node karena ada beberapa aktivitas pengguna yang bergerak menuju Masjid Nurul Azhar.

c. Taman Apkasi yang ada pada sebelah selatan wilayah studi adalah termasuk simpul kawasan karena keberadaannya menjadikan taman Apkasi sbagai tujuan pergerakan.

5. Landmark (tengeran)

Landmark adalah elemen eksternal dan merupakan bentuk visual dan menonjol dari suatu kawasan/kota. Koridor Jalan Raya Porong memeliki beberapa landmark atau tengeran yaitu kawasan bencana lumpur, makam islam, dan Masjid Nurul Azhar. Batas tanggul terluar secara visual sangat tampak pada saat melewati jalur ini.dengan adanya tanggul lumpur itu juga semakin memperjelas node atau simpul kawasan di koridor Jalan Raya Porong.

\section{PEMBAHASAN}

Berdasarkan analisis ruang terbuka hijau konsep dasar penataan koridor Jalan Raya Porong adalah menciptakan ruang terbuka hijau koridor jalan yang fungsional dalam memperbaiki iklim mikro, mereduksi bising dan polusi, nyaman serta estetik.Konsep jarak dari peletakan setiap vegetasi yang ada pada koridor Jalan Raya Porong juga berpedoman pada Masterplan ruang terbuka hijau kabupaten Sidoarjo tahun 2010.Jenis tanaman yang digunakan dalam penerapan konsep penataan di koridor Jalan Raya Porong berpedoman pada Permen PU No.05/PRT/M/2008 tentang pedoman penyedian dan pemanfaatan ruang terbuka hijau di kawasan perkotaan, hal ini dikarenakan untuk mendukung kesesuaiankondisi tapak dan agar lebih mempermudah dalam perawatan.Konsep penataan ruang terbuka hijaudi koridor Jalan Raya Porong terbagi menjadi konsep tata hijau dan konsep taman lingkungan.

a. Tata hijau peneduh

Berdasarkan hasil analisis ruang terbuka hijau yang menjelaskan bahwa kawasan koridor Jalan Raya Porong adalah kawasan yang panas maka konsep penataan vegetasi dikembangkan menjadi konsep tata hijau peneduh. Konsep tata hijau peneduh dikembangkan pada ruang sekitar jalur sirkulasi dan taman lingkungan, di tujukan untuk meningkatkan kenyamanan pengguna saat berada di dalam tapak. Berdasarkan Masterplan ruang terbuka hijau Kabupaten Sidoarjo tanaman yang digunakan sama untuk setiap segmen dan ditanam secara berbaris, tanaman yang di gunakan memiliki karakteristik berupa tajuk lebar dan berbentuk bulat. Tanaman yang digunakan adalah kelompok pohon sedang $(6-15 \mathrm{~m})$ dan pohon tinggi $(>15 \mathrm{~m})$. Tanaman yang digunakan seperti Tanjung (Mimuseps Elengi), Angsana (Ptherocorphus Indicus), Krey Payung (Filiciun decipiens) dll. Berdasarkan hasil analisa ruang terbuka hijau pemilihan jenis vegetasi jenis angsana sangat tepat karena jenis pohon ini bisa tumbuh dengan baik di lingkungan yang 
panas dan tandus seperti koridor Jalan Raya Porong.

b. Tata hijau pengarah

Konsep tata hijau pengarah di letakan di sepanjang jalur pedestrian. Tanaman yang digunakan memiliki batang tegak dan memberi kesan vertikal dan ornamental. Di tanam sepanjang jalur sirkulasi pembatas pejalan kaki setelah tanaman dengan jarak tanam $5 \mathrm{~m}$ dengan metode penanaman dilakukan secara berbaris sepanjang segmen. Tanaman tersebut merupakan tanaman baru dan yang menggunakan jenis palem diantaranya: Palem sabal (Sabal spp.), Palem hijau (Ptycosperma macarthurii), Palem sadeng (Livistona rotundifolia), Palem raja (Roystonea regia), Palem putri (Veitchia merillii), Palem sadeng (Livistona rotundifolia), Palem pigagetta (Pigagetta martelli), dll.

c. Tata hijau pengendali bising

Konsep tata hijau pengendali bising di fungsikan untuk mengurangi intensitas suara kendaraan yang melintas dan menciptakan kenyamanan bagi pengguna. Konsep tata hijau pengendali bising diletakan di sepanjang jalur sirkulasi kendaraan setelah jalur pedestrian. Menurut Masterplan Ruang Terbuka Hijau Sidoarjo tahun 2010 kemampuan tanaman mereduksi bising di pengaruhi oleh ketebalan dan kelenturan daun, ditanam berbaris atau membentuk massa, jarak tanam rapat. Tanaman yang dapat mereduksi bising antara lain Tanjung (Mimuseps Elengi), Angsana (Ptherocorphus Indicus), Cemara (Cassuarina equisetifolia), Kiara Payung (Felicium decipiens), Kembang sepatu (Hibiscus rosa sinensis).

d. Tata hijau penyerap polutan

Konsep tata hijau penyerap polutan dikembangkan untuk menyerap polutan yang berasal dari kendaraan. Kriteria tanaman untuk penyerap polutan partikel adalah tanaman yang memiliki trikoma tinggi atau memiliki bulu, bergerigi atau bersisik. Untuk polutan gas adalah tanaman yang memiliki tingkat kondusktans gas pada daun tinggi, daun tipis, memiliki stomata yang banyak, laju fotosintesa tinggi dan ditanam jarak rapat. Tanaman yang konsepkan adalah Oliander (Neium oleander), Angsana (Ptherocorphus Indicus), Biola cantik (Ficus lyrata) dan Ketapang (Terminalia catappa), Bougenville (Bougenvillea Sp), The-tehan pangkas (Achalipa sp) dll.

e. Tata hijau pembatas

Konsep tata hijau pembatas di kembangkan untuk membatasi pengguna dari pemandangan yang kurang bagus dan dari silau lampu kendaran lawan arah. Membatasi jalur sirkulasi pejalan kaki baik pada median jalan maupun bahu jalan dengan jalur kendaraan dan menambah keamanan pengguna saat berada di dalam tapak. Tanaman yang di gunakan adalah semak yang ditanam secara masal.Tanaman yang digunakan adalah Teh-tehan (Acalypha macropyhlla), Glodogan Tiang (Poyalthia lomgifolia), Soka (Ixora sinensis), Palem wregu (Rhapis excelsa) dll.

\section{f. Tata hijau estetis}

Konsep tata hijau estetis bertujuan untuk memberikan nilai estetika da meningkatkan kualitas tapak.Konsep tata hijau estetis diletakkan pada sepanjang jalur sirkulasi dekat dengan jalur pedestrian.Tanaman yang digunakan adalah tanaman dengan bunga indah dan memiliki daun yang khas. Tanaman yang digunakan diantaranya Kamboja (Plumeria rubra), Bunga kupu-kupu (Bauhinia purpurea), Kembang Sepatu (Hibiscus rosa sinensis), Bougenville (Bougenvillea Sp), Palem pigagetta (Pigagetta martelli), palem bishmark (Bicmarkia sp) dll.

g. Taman lingkungan

Konsep taman lingkungan akan dibuat disebelah barat Jalur koridor Raya Porong dengan memanfaatkan lahan kosong yang tersedia. Konsep luasan taman lingkungan \pm $5000 \mathrm{~m}^{2}$ dengan lebar $50 \mathrm{~m}$ dan panjang $100 \mathrm{~m}$. Konsep taman lingkungan memeliki tujuan menghadirkan fungsi sebagai penunjang aktivitas masyarakat, yaitu adanya kombinasi antara ruang terbuka dan area teduh. Selain itu juga akan dikonsepkan sarana dan prasarana yang disesuaikan dengan kebutuhan dan aktivitas masyarakat (bangku, gazebo, Lampu, tempat sampah,tempat bermain, toilet dll) diharapkan akan mendukung kegiatan yang ada pada tapak. Pada konsep perkerasan akan mengunakan material perpaduan antara bahan buatan dan alami untuk memudahkan penyerapan air (Grass Block). Berdasarkan Permen PU No.05/PRT/M/2008 tentang pedoman penyedian dan pemanfaatan ruang terbuka hijau di kawasan perkotaan ada beberapa kriteria pemilihan vegetasi untuk taman lingkungan dan taman kota adalah sebagai berikut:

a. Tidak beracun, tidak berduri, dahan tidak mudah patah, perakaran tidakmengganggu pondasi 


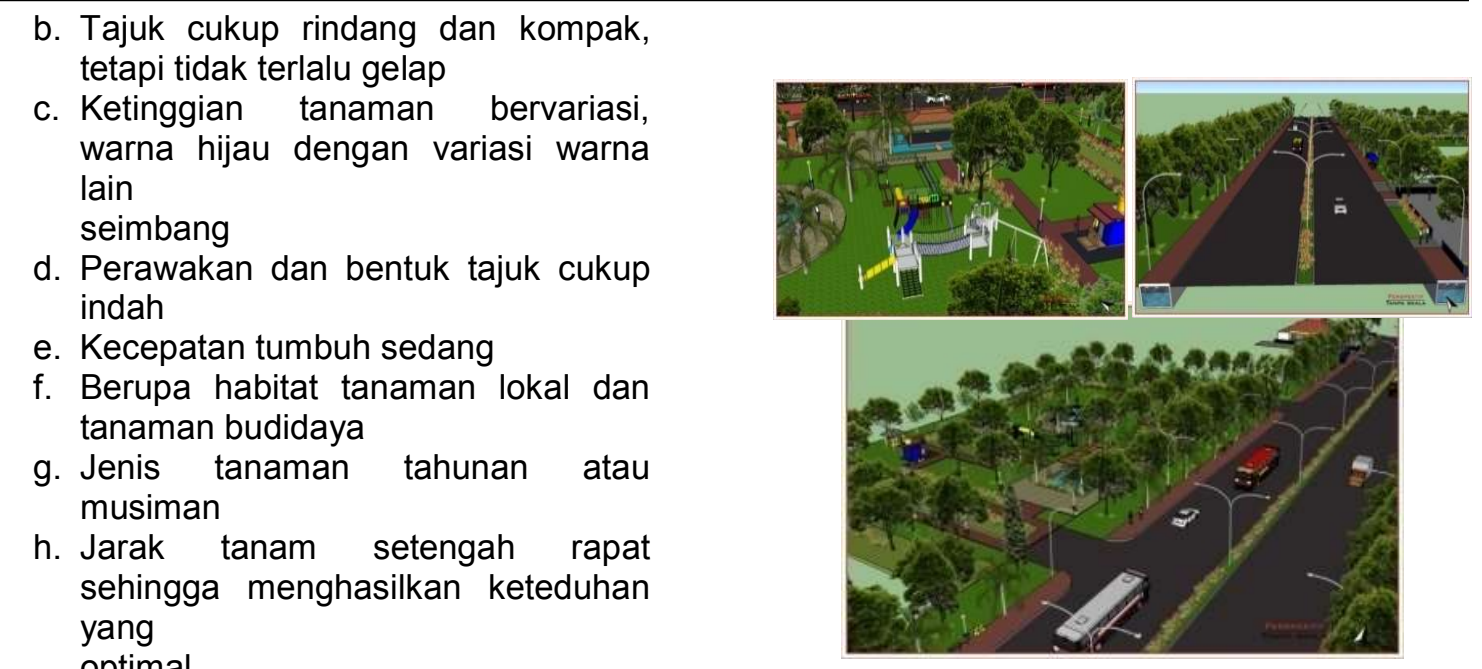
optimal

i. Tahan terhadap hama penyakit tanaman

j. Mampu menjerap dan menyerap cemaran udara

k. Sedapat mungkin merupakan tanaman yang mengundang burung

Konsep penataan vegetasi pada taman lingkungan yang mampu menyerap polusi dan debu dengan tajuk pohon yang rapat untuk menciptakan area teduh serta vegetasi dengan perpaduan warna dan tekstur daun untuk menambah keindahan kawasan (pohon angsana, cemara, palem bismark, palem pigagetta, glodogan tiang, bougenville, dan kembang sepatu, Permen PU No.05/PRT/M/2008). Pemilihan pohon beralasan demi mempermudah tingkat perawatan dan menyesuaikan dengan lingkungan. Penerapan ornament udang dan ikan bandeng pada maerial-material lansekap akan dihadirkan dalam konsep penataan taman lingkungan untuk semakin memeperjelas citra atau image kota.
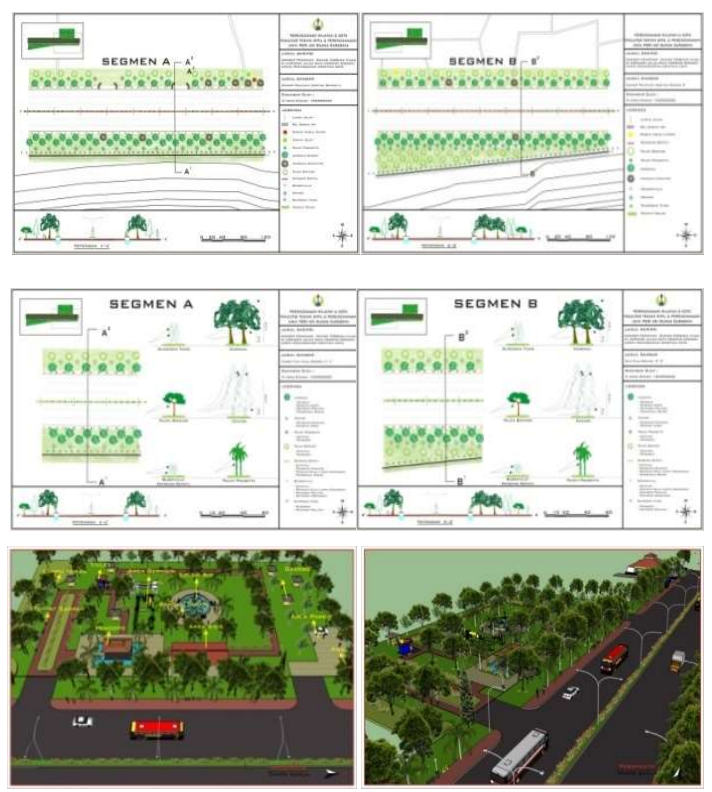

Gambar 5. Konsep Peataan RTH Koridor jalan Raya Porong

\section{KESIMPULAN DAN SARAN \\ Kesimpulan}

Karateristik persebaran ruang terbuka hijau di koridor Jalan Raya Porong terbagi menjadi dua yaitu ruang terbuka hijau dan ruang terbuka non hijau. Berdasarkan data primer dari hasil observasi ruang terbuka hijau mengasumsikan prosentase ruang tebuka hijau yang ada pada koridor Jalan Raya Porong sebesar $15 \%$, ruang terbuka non hijau sebesar $80 \%$,dan sisanya $5 \%$ adalah penggunaan sebagai fasilitas umum.

Konsep dasar penataan koridor Jalan Raya Porong adalah menciptakan ruang terbuka hijau koridor jalan yang fungsional dalam memperbaiki iklim mikro, mereduksi bising dan polusi, nyaman serta estetik.Berdasarkan Permen No. 05 tahun 2008 tentang pedoman penyediaan dan pemanfaatan ruang terbuka hijua kawasan perkotaan menjadi dasar acuan konsep penataan ruang terbuka hijau sehingga mewujudkan suasana tapak yang indah, asri serta bernilai estetik. Penerapkan konsep penataan tapak akan dikembangkan dengan menggabungkan tanaman peneduh, tanaman pengarah, tanaman penahan angin, tanaman pereduksi polutan, dan tanaman estetik dilengkapi dengan fasilitas dan utilitas bagi pengguna.

Koridor Jalan Raya Porong dikonsep untuk menjadi jalur hijau yang dapat memberikan kenyamanan kepada pengguna dengan penyediaan jalur sirkulasi kendaraan maupun jalur sirkulasi pejalan kaki. Dengan memanfaatkan lahan kosong yang ada disekitar jalur maka akan dikonsepkan sebuah taman lingkungan dengan fungsi 
mengurangi dampak negatif arus lalu lintas terhadap lingkungan, meningkatkan kualitas estetika serta dapat difungsikan sebagai rest area bagi pengguna jalur maupun masyarakat sekitar.

Penataan ruang terbuka hijau yang dikonsepkan terdiri dari tata hijau peneduh, tata hijau pengarah, tata hijau pengendali bising, tata hijau penyerap polutan, tata hijau pembatas dan tata hijau estetis dengan jarak penanaman pada setiap fungsi vegetasi berbeda-beda.Pedoman konsep tersebut yaitu kebijakan RTRW Kabupaten Sidoarjo yang menerangkan bahwa Porong termasuk dalam kawasan pengendalian bencana lumpur.

Hasil studi konsep penataan ruang terbuka hijau di koridor Jalan Raya Porong ini dapat dijadikan rujukan atau pertimbangan bagi DKP (Dinas Kebersihan dan Pertamanan) selaku pengelola pertamanan dan jalur hijau untuk penentuan program pembangunan taman dan jalur hijau di kabupaten Sidoarjo di waktu yang akan datang. Serta dapat dijadikan sebagai acuan konsep taman dan jalur hijau lainnya sehingga dapat meningkatkan kualitas ruang terbuka hijau dan nilai estetik.

\section{Saran}

Penelitian ini diharapkan akan dapat bermanfaat untuk kepentingan kegiatan akademis sehingga dapat bermanfaat bagi penelitian selanjutnya.Ruang terbuka hijau perkotaan diupayakan dalam setiap konsepnya selalu dihadirkan sebuah ciri khas atau landmark pada setiap maerialmaterial lansekap sehingga dapat menjelaskan atau mengambarkan identitas suatu

\section{DAFTAR PUSTAKA}

Anthony J. Catanse. 1984. Pengantar Perancangan Kota. Jakarta; Erlangga.

Departemen Pekerjaan Umum. Peraturan Menteri Dalam Negeri No. 01 Tahun 2007 Tentang

Penataan Ruang Terbuka Hijau Kawasan Perkotaan. Jakarta. Departemen Pekerjaan Umum.

Departemen Pekerjaan Umum. 2008. Peraturan Menteri Pekerjaan Umum No. 5 Tahun 2008 tentang Pedoman Penyediaan dan Pemanfaatan Ruang Terbuka Hijau di Kawasan Perkotaan. Jakarta. Departemen Pekerjaan Umum.

http://Masterplan RTH Sidoarjo EDUKASI.htm.(diakses 30 Desember 2013 10.45)

Kementrian Dalam Negeri. 2007. Undang-undang No. 26 Tahun 2007 tentang Penataan Ruang. Jakarta. Kementrian Dalam Negeri.

Masterplan Ruang Terbuka Hijau Sidoarjo tahun 2010-2030.

Putri, Dirthasia Gemilang. 2012. Konsep Penataan Ruang Terbuka Hijau Di Kawasan Pusat Kota Ponorogo. Skripsi Institut Pertanian Bogor, Bogor.

Syahroji. 2008. Perancangan Ulang Jalur Hijau Jalan Barat-Timur Kota Baru Bandar Kemayoran. Skripsi Institut Pertanian Bogor, Bogor.

Zhan, Markus. 1999. Perancangan Kota Secara Terpadu. Yogyakarta; Kasiniu 